\title{
DNA nanotechnology-based development of delivery systems for bioactive compounds.
}

\section{$\operatorname{AUTHOR}(\mathrm{S}):$}

Mohri, Kohta; Nishikawa, Makiya; Takahashi, Yuki; Takakura, Yoshinobu

\section{CITATION:}

Mohri, Kohta ...[et al]. DNA nanotechnology-based development of delivery systems for bioactive compounds.. European journal of pharmaceutical sciences : official journal of the European Federation for Pharmaceutical Sciences 2014, 58: 26-33

\section{ISSUE DATE:}

2014-07-16

URL:

http://hdl.handle.net/2433/187365

\section{RIGHT:}

(c) 2014 Elsevier B.V.; This is not the published version. Please cite only the published version.; この論文は出版社版でありません。引用の際に は出版社版をご確認ご利用ください。 


\title{
DNA nanotechnology-based development of delivery systems for bioactive compounds
}

Kohta Mohri, Makiya Nishikawa, Yuki Takahashi, and Yoshinobu Takakura*

Department of Biopharmaceutics and Drug Metabolism, Graduate School of Pharmaceutical Sciences, Kyoto University, Sakyo-ku, Kyoto 606-8501, Japan

\begin{abstract}
Nucleic acids, DNA and RNA, not only allow transfer and replication of densely coded genetic information, but also act as danger signals triggering innate immune response. Recent progress in the design and construction of nano-sized structures using DNA has opened a new field of nanotechnology. The unique properties of nano-sized DNA constructs can be exploited to develop programmable materials for efficient delivery of bioactive compounds. In this review, recent advances in DNA nanotechnology and its applications as delivery systems are summarized. In particular, we focus on the delivery of DNA containing unmethylated cytosine-phosphate-guanine $(\mathrm{CpG})$ dinucleotide, or CpG motif, to immune cells expressing Toll-like receptor 9. Recent studies have shown that precisely designed DNA constructs, such as multi-branched DNA, polyhedral DNA, and DNA origami, can be used to enhance the biological activity of CpG DNA.
\end{abstract}

Keywords: DNA nanotechnology, Drug delivery system, CpG DNA, Immune response 


\section{Introduction}

For millions of years, living organisms have used nucleic acids, DNA and RNA, to encode, transfer, decode, and transcribe genetic information. This is largely attributed to the nature of the nucleic acids to form a double-stranded structures with a complementary strand (Watson and Crick, 1974), and the double-strand formation keeps the genetic information unchanged (Crick, 1970). Recently, this ability to form double-stranded structures has been exploited to construct a variety of unnatural tertiary DNA structures-DNA-based nano-scale materials. To date, DNA nanotechnology has been used in optical detection, diagnostics, and drug delivery (Seeman, 2010; Roh et al., 2011b; Hartman et al., 2013).

From a structural perspective, there are many advantages of using DNA as a building block for developing diagnostic and therapeutic materials. The classical right-handed double helical DNA, B-DNA, is a nano-scale species; the diameter and helical rise of B-DNA is about $2 \mathrm{~nm}$ and $0.34 \mathrm{~nm} / \mathrm{base}$, respectively (Leslie et al., 1980). Two DNA molecules can be ligated to form one species via DNA ligase-catalyzed reactions (Figure 1A). Single-stranded overhangs, called sticky ends, are used for the ligation of DNA molecules (Wu and Wallace, 1989). This permits the custom-fabrication of readily programmable intermolecular connections and allows us to synthesize desired DNA structures with varying functions (Lee et al., 2009). Branched DNA with junction points has also been used as building blocks. A typical branched DNA forms a four-armed Holliday junction, an intermediate structure formed during the process of genetic recombination (Holliday, 1964; Shinagawa and Iwasaki, 1995). In addition, Y-shaped (Y-DNA) and X-shaped (X-DNA) DNAs have been designed and synthesized using three or four oligodeoxynucleotides (ODNs), respectively, with the halves of each ODN being partially complementary to a half of each of the other two ODNs (Kallenbach et al., 1983; Ma et al., 1986) (Figure 1B). The branched DNA can be used to create two- or three-dimensional networked structures (Seeman, 1982).

These approaches enable us to develop several types of self-assembled and bottom-up tertiary DNA structures. DNA is a highly homogeneous and inexpensive material which can be obtained by total synthesis. In addition, DNA is a chemically stable molecule. Chemical modification of the functional groups of DNA can also be possible. These properties of DNA are the advantages of DNA-based delivery systems.

Recent studies have found that DNA nanostructures are useful for pharmaceutical and biomedical applications (Nishikawa et al., 2010). DNA or RNA containing specific sequences, such as antisense ODN, decoy ODN, small interfering RNA (siRNA), and 
unmethylated cytosine-phosphate-guanine $(\mathrm{CpG})$ ODN, has several biological functions, including the inhibition of expression of target molecules and the activation of innate immunity (Dove, 2002; Fattal and Bochot, 2006; Krishnamachari and Salem, 2009; Tomita et al., 2003). DNA nanostructures constructed using functional nucleic acids could improve or strengthen their biological activity. Nucleic acids are degraded by nucleases in vivo (Takakura et al., 2001). This biodegradability assures that DNA and RNA are biocompatible. Therefore, oligomers and polymers consisting of DNA can be used for the development of biodegradable, biocompatible, and safe nano-scale materials. In this review, approaches to use nano-scale DNA structures exhibiting unique structural properties as drug delivery systems (DDS) are summarized.

\section{DNA nanostructures for drug delivery systems}

Pioneering work by Seeman and coworker, who constructed a DNA cube, laid the foundation for DNA nanotechnology (Chen and Seeman, 1991). Since then, a number of self-assembled polyhedral DNA nanostructures have been developed (He et al., 2008, 2010; Zhang et al., 2008, 2009, 2010; Li et al., 2012) (Figure 1C).

A group of researchers from Cornell University developed dendrimer-like DNA (DL-DNA) through the ligation of Y-DNA building blocks (Li et al., 2004; Freedman et al., 2005). Three ODNs with the halves of each ODN being complementary to a half of the other two ODNs are used to construct Y-DNA, and which are ligated to each other through the adhesive terminal ends using T4 DNA ligase. The numerous terminals of the DL-DNA can be used to conjugate any functional moieties, including fluorescent probes. Rothemund (2006) prepared materials of arbitrary two-dimensional shapes, including a smiley face, using a 7-kilobase single-stranded scaffold and over 200 short 'staple strands' to hold the scaffold in place. The multiple staple strands were hybridized to the long scaffold strand by simple annealing. This method, known as "DNA origami", allows the arrangement of a large number of ODNs with nano- to micrometer precision and made it possible to create more complex and larger structures. The DNA nanostructures developed thus far have shown enormous potential for applications in a number of fields.

Synthetic or semi-synthetic DNA or RNA has the potential to interact with target molecules, such as endogenous DNA, RNA, and proteins. Such nucleic acids can be used as therapeutic agents for the treatment of diseases. Because there are several barriers for the delivery of functional DNA and RNA, a variety of delivery systems, including liposomes, nanoparticles, polymers, and molecular conjugates, have been developed (Ma et al., 2005; Lee et al., 2012; Tsai et al., 2012; Lambert et al., 2001). 
Although cationic liposomes and polymers are frequently used for the delivery of nucleic acid drugs, there is a concern that such compounds could cause damages to the cell membrane. Hydrogels have been used for the encapsulation and sustained release of drugs (Nayak and Lyon, 2005). However, most hydrogels are prepared by polymerization and may contribute to DNA damage and cytotoxicity. Biodegradable hydrogels made of natural polymers, including gelatin and hyaluronic acid, generally lack homogeneity.

DNA nanotechnology-based methods would solve the problems associated with the delivery of nucleic acid drugs. Several examples are summarized in Table 1. Keum et al. (2011) reported that compared with their linear counterparts, tetrahedral DNA containing an antisense motif showed higher efficiency in inhibiting the expression of enhanced green fluorescent protein (EGFP) in cultured cells. Lee et al. (2012) developed tetrahedral DNA-nanoparticles of defined size and succeeded in delivering siRNAs into cancer cells, where they silenced the expression of target genes. Modification of the tetrahedral DNA with folic acid greatly enhanced the efficiency of RNA interference in folate receptor-positive cancer cells. The size of the tetrahedral DNA-nanoparticle was about $30 \mathrm{~nm}$ and this property led to a longer circulation time of the nanoparticles $\left(t_{1 / 2} \approx 24.2 \mathrm{~min}\right)$ than that of the parent $\operatorname{siRNA}\left(t_{1 / 2} \approx 6 \mathrm{~min}\right)$.

Roh et al. (2011a) developed DNAsome, a liposome-like vesicle consisting of lipid-conjugated Y-DNA. Its amphiphilic nature allowed the lipid-conjugated Y-DNA to self-assemble and form submicron particles. These authors showed that the delivery of siRNA targeting the anti-apoptotic gene Bcl-2 can be achieved by using DNAsomes. Further, the authors also showed that the delivery of the siRNA together with doxorubicin (DXR), an anti-cancer-agent, to cancer cells inhibited their proliferation. Um et al. (2006) developed DNA hydrogels by ligating Y-DNA, the X-shaped DNA (X-DNA), or T-shaped DNA. The authors reported that macromolecular drugs like insulin can be loaded into and gradually released from these hydrogels. More recently, a meta-hydrogel that has the ability to restore its original shape has also been created with DNA by employing a rolling circle amplification method (Lee et al., 2012).

Jiang et al. (2012) reported that a DNA nanostructure prepared using the DNA origami technology delivered DXR that was intercalated into the structure and inhibited the proliferation of not only MCF-7 human breast adenocarcinoma cells, but also that of doxorubicin-resistant cells. Zhao et al. (2012) developed two DNA origami-based nanostructures to deliver DXR into three different breast cancer cell lines (MDA-MB-231, MDA-MB-468, and MCF-7) and successfully induced programmed cell death. Using DNA origami method, Andersen et al. (2009) created a 
three-dimensional addressable DNA box that can be opened by an externally supplied DNA 'key'. Douglas et al. (2012) developed an aptamer-gated hexagonal barrel nanostructure. The nanostructure loaded with antibody fragments was used to trigger cell-signaling in cultured cells. These antibodies bound to cell surface receptors and inhibited the cell growth.

\section{DNA-mediated stimulation of innate immunity}

Mammalian innate immune system recognizes damage-associated molecular patterns (DAMPs) and pathogen-associated molecular patterns (PAMPs) as danger signals. Several DNA or RNA sensors have recently been identified in mammalian cells (Ozinsky et al., 2000). The recognition of nucleic acids by these sensors produces type I interferons (IFNs) and proinflammatory cytokines and upregulates the expression of costimulatory molecules (Figure 2). These responses could be used in the treatment of some diseases (Ishii and Akira, 2007).

\subsection{DNA/RNA sensors}

Toll-like receptors (TLRs) play essential roles in the activation of innate immune responses through the recognition of PAMPs expressed on a wide array of microbes and endogenous DAMPs released from stressed or dying cells (Adams, 2009; Matzinger, 1994; Rakoff-Nahoum et al., 2004). TLR3, TLR7/8, or TLR9 recognizes exogenous or endogenous RNA/DNA in endosomal vesicles (Kawai and Akira, 2006). Viral, bacterial, and mammalian DNAs binds to TLR9, but microbial DNA is more efficient in activating the innate immune system compared with self DNA (Krieg, 2002). This is because, bacterial and viral DNAs harbor $\mathrm{CpG}$ motifs with much higher frequency compared with mammalian DNA (Bird, 1987). Bacterial and viral DNAs contain many CpG motifs, which is unmethylated cytosine-phosphate-guanine dinucleotides, whereas CG dinucleotides in mammalian DNA is highly methylated at the C5 position of cytosine. Thus, TLR9 is a receptor for microbial DNA containing $\mathrm{CpG}$ motifs (CpG DNA) but does not recognize methylated $\mathrm{CpG}$ dinucleotides in mammalian DNA (Tokunaga et al., 1988). TLR9 ligation recruits myeloid differentiation primary response protein 88 (MyD88) and activates downstream signaling pathways (Kawai et al., 2004). The activated TLR9-positive cells, including dendritic cells and macrophages, secrete proinflammatory cytokines and type I IFNs (Uematsu and Akira, 2007). Because double-stranded RNA and single-stranded RNA, respectively, are the ligands of TLR3 and TLR7/8, bacterial and viral RNAs are recognized by these TLRs, and induce the production of type I IFNs (Kawai and Akira, 2006). 
Other DNA sensors identified include DNA-dependent activator of IRFs (DAI) and Z-DNA binding protein 1 (ZBP1) (Takaoka et al., 2007; Wang et al., 2008). DAI interacts directly with double-stranded DNA in the cytoplasm and is capable of activating interferon regulatory factor 3 (IRF3), leading to the production of type-I IFNs. Several cytosolic RNA sensors, including retinoic acid-inducible gene I (RIG-I), melanoma differentiation-associated gene 5 (MDA5), and probable ATP-dependent RNA helicase DHX58 (or laboratory of genetics and physiology-2; LGP2), have been identified (Swiecki et al., 2011). A cytosolic helicase, RIG-I is a key sensor of viral infection and is activated by single-stranded triphosphate RNA, which stimulates the secretion of IFN- $\alpha$ and IFN- $\beta$ from monocytes (Hornung et al., 2006; Schlee et al. 2009). Therefore, the activation of the innate immune system following the recognition of viral and synthetic RNA containing 5'-triphosphate by RIG-I can be useful for the immunotherapy of cancer. Poeck et al. (2008) reported that Bcl2-specific siRNA containing $5^{\prime}$-triphosphate ( $3 p$-siRNA) potently inhibited the growth of melanoma. It is interesting that the recognition of 3p-siRNA by RIG-I synergized with siRNA-mediated $\mathrm{Bcl} 2$ silencing to induce massive apoptosis of cancer cells.

\subsection{Therapeutic application of CpG DNA}

As mentioned above, CpG DNA is a ligand for TLR9 and triggers innate immune response. Therefore, $\mathrm{CpG}$ DNA can be used as a therapeutic agent or an adjuvant for the treatment of a wide range of diseases, including cancer, viral infection, and allergies (Smyth et al., 2000; Baron et al., 1991). However, natural CpG DNA has some drawbacks as a therapeutic agent - the natural, phosphodiester (PO) DNA or ODN is prone to enzymatic degradation, has short in vivo circulation time, and has a low membrane permeability (Emlen and Mannik, 1984; Sands et al., 1994). To overcome these obstacles, cationic liposomes and polymers have been used to deliver CpG DNA into TLR9-positive cells (Kuramoto et al., 2006; Smolarczyk et al., 2005). Additionally, a variety of chemically modified DNA analogs, including phosphorothioate (PS) ODN, 2'-O-methyl ODN, morpholinos, methylphosphonate ODN, phosphoramidate ODN, and locked nucleic acid, have been developed for achieving enhanced stability against nucleases (Wagner, 1994; Crooke, 2004a, 2004b; Grünweller et al., 2003). In particular, PS ODN that can be synthesized by simple methods is widely used in studies involving CpG DNA because of their resistance to enzymatic degradation (Stein et al., 1988). However, PS ODN binds serum proteins and cellular membranes with high affinity (Brown et al., 1994; Monteith et al., 1999). It was reported that PS-ODNs accumulate in the kidney and induce renal toxicity, including renal proximal tubular degeneration at 
high doses (Monteith et al., 1999).

The flanking sequence preferences of $\mathrm{CpG}$ motif have been extensively studied (Lenert et al., 2006; Rankin et al., 2001). The optimal flanking sequences for rodent and human TLR9 respectively are 5'-GACGTT-3' and 5'-GTCGTT-3' (Rankin et al., 2001; Yi et al., 1998). CpG DNA has been categorized into four classes: class A (also known as type D), class B (also known type K), class C, and class P. Class A CpG DNA that contains a palindrome sequence for spontaneous G-tetrad formation, forms nano-sized oligomers under physiological conditions, and induces massive secretion of type I IFNs from plasmacytoid dendritic cells (pDCs) (Kerkmann et al., 2005). In contrast, class B CpG DNA is a linear molecule and has little potency to induce the production of type I IFNs (Krug et al., 2001), but is a potent mitogenic signal for human B cells and induces the secretion of large amounts of proinflammatory cytokines (Brown et al., 1998; Yi et al., 1996). It is interesting that polystyrene nanoparticle loaded with class B CpG DNA, which is similar in size as the oligomers of class A CpG DNA, shows enhanced potency to induce IFN- $\alpha$ (Kerkmann et al., 2005). This indicates that the immune responses depend on the tertiary structures of $\mathrm{CpG}$ DNA. Class C CpG DNA stimulates the production of moderate levels of type I IFNs in pDCs and directly activates B cells (Poeck et al., 2004; Hartmann et al., 2003; Marshall et al., 2003; Vollmer et al., 2004).

\section{DNA assemblies for the delivery of CpG DNA}

Recent studies have reported that a variety of DNA-based nanostructures increase the biological activity of $\mathrm{CpG}$ DNA. Figure 3 summarizes the DNA assemblies that have been used for the delivery of CpG DNA. Soluble DNA nanostructures, including dumbbell shaped DNA, polypod-like DNA (polypodna), and dendrimer-like DNA (DL-DNA), are used for the targeted delivery of CpG DNA to TLR9-positive cells, such as dendritic cells, whereas DNA hydrogel is a formulation for sustained release of the immunostimulatory DNA. In this section, recent challenges in the delivery of $\mathrm{CpG}$ DNA using DNA nano-assemblies are summarized.

\subsection{Dumbbell shaped DNA}

Once administered, the short DNA, including CpG DNA, is quickly degraded by DNases in blood or other biological fluids (Goodchild et al., 1991). It has been reported that loop formation increases the stability of short double-stranded DNA by making its terminals unavailable to exonucleases (Chu et and Orgel, 1992; Clusel et al., 1993). Schmidt et al. (2006) designed a dumbbell-like covalently-closed PO CpG DNA (dSLIM-30L1) to increase the resistance to enzymatic degradation. The dSLIM-30L1 
was effective in inducing the production of proinflammatory cytokines, including interleukin (IL)-2 and IL-12p40. Further, its activity was comparable to that of a linear CpG DNA that contained phosphorothioate backbones at both ends. Yang et al. (2013) reported that $\mathrm{CpG}$ DNA with double stem-loop structure stimulated the proliferation of human peripheral blood mononuclear cells (PBMCs) and inhibited the growth of breast cancer in mice.

\subsection{Branched, polypod-like structured DNA}

Branched DNA is used as a building block for the construction of tertiary DNA structures because the branches can be used for connecting new DNA units. Y-DNA has a simple branched structure, and it is prepared using three ODNs with the halves of each ODN being partially complementary to the halves of the other two ODNs (Nishikawa et al., 2008; Matsuoka et al., 2010). Nishikawa et al. (2008) have previously reported that, compared to their single-stranded counterparts, Y-DNA containing three potent $\mathrm{CpG}$ motifs induces the secretion of significantly higher levels of tumor necrosis factor- $\alpha$ and interleukin-6 from RAW264.7 macrophage-like cells. The enhanced immunostimulatory activity of Y-DNA was associated with increased cellular uptake by TLR9-positive cells. Subsequently, Mohri et al. (2012a) designed and developed nano-sized, polypod-like DNA (polypodna) containing $\mathrm{CpG}$ motifs (Figure 3A). Polypodna preparations consisting of three to eight 36-mer ODNs were successfully obtained by simple annealing. All polypodnas induced the secretion of large amounts of cytokines from macrophage-like RAW264.7 cells. Mohri et al. (2012a) found that increasing the number of pods increased the cellular uptake, but reduced the biological stability. Loop formation at the terminals of tetrapodna increased the stability in mouse serum and led to higher immunostimulatory activity than tetrapodna without loops (Mohri et al., $2012 b$ ). High activity of the polypodna preparations were also observed after addition to human PBMCs (Uno et al., in press).

\subsection{Dendrimer-like DNA and DNA hydrogel}

Ligation of several polypodnas with overhangs at the 5'-ends using T4 DNA ligase results in the formation of DL-DNA (Figure 3B). Rattanakiat et al., (2009) have developed the second and third generations of DL-DNA containing respectively 12 or 24 highly potent $\mathrm{CpG}$ motifs in one unit. These DL-DNAs exhibit significantly high immunostimulatory activity compared with their individual components, including the CpG motif-containing tripodna. Further, a DNA hydrogel was also prepared by the ligation of polypodna with overhangs at all of the $5^{\prime}$-ends of a palindromic sequence 
(Um et al., 2006). Nishikawa et al., (2011) developed DNA hydrogel with immunostimulatory CpG DNA by connecting tetrapodna preparations (Figure 3C). The CpG DNA hydrogel induced cytokine release from immune cells and gradually released DXR. Administration of CpG DNA hydrogel containing DXR effectively inhibited the growth of colon 26 tumor in mice.

\subsection{Tetrahedron DNA}

Goodman and coworkers developed a method for single-step synthesis of a tetrahedral DNA nanostructure (Goodman et al., 2004). Li et al. (2011) designed and prepared functional, multivalent DNA nanostructures by appending CpG DNA to tetrahedral DNA. The tetrahedral DNA with CpG motifs was efficiently taken up by TLR9-positive cells and activated the downstream pathways to induce the secretion of various proinflammatory cytokines at high concentrations. The stability of tetrahedral DNA nanostructure was higher than that of double-stranded DNA in fetal bovine serum and in cells. Liu et al. (2012) used CpG DNA-containing tetrahedral DNA nanostructure as a vehicle for the delivery of streptavidin, a model antigen. The precisely designed nano-sized complexes induced strong and long-lasting antigen-specific responses in mice without stimulating reaction to the DNA nanostructure itself, indicating that tetrahedral DNA has the potential to serve as a general platform for vaccine delivery.

\subsection{DNA origami tube}

The DNA origami technique has also been used to synthesize complex DNA structures (Castro et al., 2011). Some DNA origami-based assemblies can be used as scaffolds for chemical and biological processes (Simmel, 2012). The structural patterns of DNA origami technique-based tubes are programmable (Castro et al., 2011). Further, the surface of the DNA tube can be modified with a wide variety of biomolecules, including proteins and nucleic acids. Such modification could extend the use of DNA tubes into biomedical applications. Schüller et al. (2011) developed a tube-shaped DNA origami structure consisting of 30 parallel double-helices that were covered with 62 $\mathrm{CpG}$ ODNs. This DNA origami tube triggered a strong immune response as characterized by cytokine production and activation of freshly isolated spleen cells.

\section{Conclusion}

The field of DNA technology is rapidly growing with the realization that DNA can be useful as a generic material. In this review, we summarized the recent advances in the development of DNA nanotechnology-based systems consisting of self-assembled 
DNA nanostructures. Since these DNA structures can be freely designed and are programmable, their structural properties can be and should be tuned for specific applications. Available information clearly suggests that DNA nanostructures offer promising new avenues for the delivery of immunostimulatory nucleic acids to immune cells expressing their receptors. We believe that precisely designed DNA nanostructures will be used in the treatment of a variety of diseases in the near future. 


\section{References}

Adams, S., 2009. Toll-like receptor agonists in cancer therapy. Immunotherapy 1, 949-964.

Andersen, E.S., Dong, M., Nielsen, M.M., Jahn, K., Subramani, R., Mamdouh, W., Golas, M.M., Sander, B., Stark, H., Oliveira, C.L., Pedersen, J.S., Birkedal, V., Besenbacher, F., Gothelf, K.V., Kjems, J., 2009. Self-assembly of a nanoscale DNA box with a controllable lid. Nature 459, 73-76.

Baron, S., Tyring, S.K., Fleischmann, Jr. W.R., Coppenhaver, D.H., Niesel, D.W., Klimpel, G.R., Stanton, G.J., Hughes, T.K., 1991. The interferons. Mechanisms of action and clinical applications. JAMA 266, 1375-1383.

Bird, A.P., 1987. CpG islands as gene markers in the vertebrate nucleus. Trends Genet 3, 342-347.

Brown, D.A., Kang, S.H., Gryaznov, S.M., DeDionisio, L., Heidenreich, O., Sullivan, S., $\mathrm{Xu}, \mathrm{X}$., Nerenberg, M.I., 1994. Effect of phosphorothioate modification of oligodeoxynucleotides on specific protein binding. J. Biol. Chem. 269, 26801-26805.

Brown, W.C., Estes, D.M., Chantler, S.E., Kegerreis, K.A., Suarez, C.E., 1998. DNA and a $\mathrm{CpG}$ oligonucleotide derived from Babesia bovis are mitogenic for bovine $\mathrm{B}$ cells. Infect. Immun. 66, 5423-5432.

Castro, C.E., Kilchherr, F., Kim, D.N., Shiao, E.L., Wauer, T., Wortmann, P., Bathe, M., Dietz, H., 2011. A primer to scaffolded DNA origami. Nat. Methods. 8, 221-229.

Chen, J.H., Seeman, N.C., 1991. Synthesis from DNA of a molecule with the connectivity of a cube. Nature 350, 631-633.

Chu, B.C., Orgel, L.E., 1992. The stability of different forms of double-stranded decoy DNA in serum and nuclear extracts. Nucleic Acids Res. 20, 5857-5858.

Clusel, C., Ugarte, E., Enjolras, N., Vasseur, M., Blumenfeld, M., 1993. Ex vivo regulation of specific gene expression by nanomolar concentration of double-stranded dumbbell oligonucleotides. Nucleic Acids Res. 21, 3405-3411.

Crick, F., 1970. Central dogma of molecular biology. 227, 561-563.

Crooke, S.T., 2004a. Antisense strategies. Curr. Mol. Med. 4, 465-487.

Crooke, S.T., 2004b. Progress in antisense technology. Annu. Rev. Med. 55, 61-95.

Douglas, S.M., Bachelet, I., Church, G.M., 2012. A logic-gated nanorobot for targeted transport of molecular payloads. Science 335, 831-834.

Dove, A., 2002. Antisense and sensibility. Nat. Biotechnol. 20, 121-124.

Emlen, W., Mannik, M., 1984. Effect of DNA size and strandedness on the in vivo clearance and organ localization of DNA. Clin. Exp. Immunol. 56, 185-192. 
Fattal, E., Bochot, A., 2006. Ocular delivery of nucleic acids: antisense oligonucleotides, aptamers and siRNA. Adv. Drug Deliv. Rev. 58, 1203-1223.

Freedman, K.O., Lee, J., Li, Y., Luo, D., Skobeleva, V.B., Ke, P.C., 2005. Diffusion of single star-branched dendrimer-like DNA. J. Phys. Chem. B. 109, 9839-9842.

Goodchild, J., Kim, B., Zamecnik, P.C., 1991. The clearance and degradation of oligodeoxynucleotides following intravenous injection into rabbits. Antisense Res. Dev. 1, 153-60.

Goodman, R.P., Berry, R.M., Turberfield, A.J., 2004. The single-step synthesis of a DNA tetrahedron. Chem. Commun. 1372-1373.

Grünweller, A., Wyszko, E., Bieber, B., Jahnel, R., Erdmann, V.A., Kurreck, J., 2003. Comparison of different antisense strategies in mammalian cells using locked nucleic acids, 2'-O-methyl RNA, phosphorothioates and small interfering RNA. Nucleic Acids Res. 31, 3185-3193.

Hartman, M.R., Ruiz, R.C., Hamada, S., Xu, C., Yancey, K.G., Yu, Y., Han, W., Luo, D., 2013. Point-of-care nucleic acid detection using nanotechnology. Nanoscale. 5, 10141-10154.

Hartmann, G., Battiany, J., Poeck, H., Wagner, M., Kerkmann, M., Lubenow, N., Rothenfusser, S., Endres, S., 2003. Rational design of new $\mathrm{CpG}$ oligonucleotides that combine B cell activation with high IFN-alpha induction in plasmacytoid dendritic cells. Eur. J. Immunol. 33, 1633-1641.

He, Y., Su, M., Fang, P.A., Zhang, C., Ribbe, A.E., Jiang, W., Mao, C., 2010. On the chirality of self-assembled DNA octahedra. Angew. Chem., Int. Ed. 49, 748-751.

He, Y., Ye, T., Su, M., Zhang, C., Ribbe, A.E., Jiang, W., Mao, C., 2008. Hierarchical self-assembly of DNA into symmetric supramolecular polyhedral. Nature 452, 198-201.

Holliday, R., 1964. A mechanism for gene conversion in fungi. Genet. Res. 5, 282-304.

Hornung, V., Ellegast, J., Kim, S., Brzózka, K., Jung, A., Kato, H., Poeck, H., Akira, S., Conzelmann, K.K., Schlee, M., Endres, S., Hartmann, G., 2006. 5'-Triphosphate RNA is the ligand for RIG-I. Science 314, 994-997.

Ishii, K.J., Akira, S., 2007. Toll or toll-free adjuvant path toward the optimal vaccine development. J. Clin. Immunol. 27, 363-371.

Jiang, Q., Song, C., Nangreave, J., Liu, X., Lin, L., Qiu, D., Wang, Z.G., Zou, G., Liang, X., Yan, H., Ding, B., 2012. DNA origami as a carrier for circumvention of drug resistance. J. Am. Chem. Soc. 134, 13396-133403.

Kallenbach, N.R., Ma, R.I., Seeman, N.C., 1983. An immobile nucleic acid junction constructed from oligonucleotides. Nature 305, 829-831. 
Kawai, T., Akira, S., 2006. Innate immune recognition of viral infection. Nat. Immunol. 7, 131-137.

Kawai, T., Sato, S., Ishii, K.J., Coban, C., Hemmi, H., Yamamoto, M., Terai, K., Matsuda, M., Inoue, J., Uematsu, S., Takeuchi, O., Akira, S., 2004. Interferon-alpha induction through Toll-like receptors involves a direct interaction of IRF7 with MyD88 and TRAF6. Nat. Immunol. 5, 1061-1068.

Kerkmann, M., Costa, L.T., Richter, C., Rothenfusser, S., Battiany, J., Hornung, V., Johnson, J., Englert, S., Ketterer, T., Heckl, W., Thalhammer, S., Endres, S., Hartmann, G., 2005. Spontaneous formation of nucleic acid-based nanoparticles is responsible for high interferon-alpha induction by $\mathrm{CpG}-\mathrm{A}$ in plasmacytoid dendritic cells. J. Biol. Chem. 280, 8086-8093.

Keum, J.W., Ahn, J.H., Bermudez, H., 2011. Design, assembly, and activity of antisense DNA nanostructures. Small 7, 3529-3535.

Krieg, A.M., 2002. CpG motifs in bacterial DNA and their immune effects. Annu. Rev. Immunol. 20, 709-760.

Krishnamachari, Y., Salem, A.K., 2009. Innovative strategies for co-delivering antigens and CpG oligonucleotides. Adv. Drug Deliv. Rev. 61, 205-217.

Krug, A., Rothenfusser, S., Hornung, V., Jahrsdorfer, B., Blackwell, S., Ballas, Z.K., Endres, S., Krieg, A.M., Hartmann, G., 2001. Identification of CpG oligonucleotide sequences with high induction of IFN-alpha/beta in plasmacytoid dendritic cells. Eur. J. Immunol. 31, 2154-2163.

Kuramoto, Y., Nishikawa, M., Hyoudou, K., Yamashita, F., Hashida, M., 2006. Inhibition of peritoneal dissemination of tumor cells by single dosing of phosphodiester $\mathrm{CpG}$ oligonucleotide/cationic liposome complex. J. Control. Release. $115,226-233$.

Lambert, G., Fattal, E., Couvreur, P., 2001. Nanoparticulate systems for the delivery of antisense oligonucleotides. Adv. Drug Deliv. Rev. 47, 99-112.

Lee, H., Lytton-Jean, A.K., Chen, Y., Love, K.T., Park, A.I., Karagiannis, E.D., Sehgal, A., Querbes, W., Zurenko, C.S., Jayaraman, M., Peng, C.G., Charisse, K., Borodovsky, A., Manoharan, M., Donahoe, J.S., Truelove, J., Nahrendorf, M., Langer, R., Anderson, D.G., 2012. Molecularly self-assembled nucleic acid nanoparticles for targeted in vivo siRNA delivery. Nat. Nanotechnol. 7, 389-393.

Lee, J.B., Peng, S., Yang, D., Roh, Y.H., Funabashi, H., Park, N., Rice, E.J., Chen, L., Long, R., Wu, M., Luo, D., 2012. A mechanical metamaterial made from a DNA hydrogel. Nat. Nanotechnol. 7, 816-820.

Lee, J.B., Roh, Y.H., Um, S.H., Funabashi, H., Cheng, W., Cha, J.J., Kiatwuthinon, P., 
Muller, D.A., Luo, D., 2009. Multifunctional nanoarchitectures from DNA-based ABC monomers. Nat. Nanotechnol. 4, 430-436.

Lee, S.J., Huh, M.S., Lee, S.Y., Min, S., Lee, S., Koo, H., Chu, J.U., Lee, K.E., Jeon, H., Choi, Y., Choi, K., Byun, Y., Jeong, S.Y., Park, K., Kim, K., Kwon, I.C., 2012. Tumor-homing poly-siRNA/glycol chitosan self-cross-linked nanoparticles for systemic siRNA delivery in cancer treatment. Angew. Chem. Int. Ed. Engl., 51, 7203-7207.

Lenert, P., Goeken, A.J., Ashman, R.F., 2006. Extended sequence preferences for oligodeoxyribonucleotide activity. Immunology 117, 474-481.

Leslie, A.G., Arnott, S., Chandrasekaran, R., Ratliff, R.L., 1980. Polymorphism of DNA double helices. J. Mol. Biol. 143, 49-72.

Li, J., Pei, H., Zhu, B., Liang, L., Wei, M., He, Y., Chen, N., Li, D., Huang, Q., Fan, C., 2011. Self-assembled multivalent DNA nanostructures for noninvasive intracellular delivery of immunostimulatory CpGoligonucleotides. ACS Nano 5, 8783-8789.

Li, X., Zhang, C., Hao, C., Tian, C., Wang, G., Mao, C., 2012. DNA polyhedra with T-linkage. ACS Nano 6, 5138-5142.

Li, Y., Tseng, Y.D., Kwon, S.Y., D'Espaux, L., Bunch, J.S., McEuen, P.L., Luo, D. 2004. Controlled assembly of dendrimer-like DNA. Nat. Mater. 3, 38-42.

Liu, X., Xu, Y., Yu, T., Clifford, C., Liu, Y., Yan, H., Chang, Y., 2012. A DNA nanostructure platform for directed assembly of synthetic vaccines. Nano Lett. 12, 4254-4259.

Ma, R.I., Kallenbach, N.R., Sheardy, R.D., Petrillo, M.L., Seeman, N.C., 1986. Three-arm nucleic acid junctions are flexible. Nucleic Acids Res. 14, 9745-9753.

Ma, Z., Li, J., He, F., Wilson, A., Pitt, B., Li, S., 2005. Cationic lipids enhance siRNA-mediated interferon response in mice. Biochem. Biophys. Res. Commun. 330, 755-759.

Marshall, J. D., Fearon, K., Abbate, C., Subramanian, S., Yee, P., Gregorio, J., Coffman, R. L., Van Nest, G., 2003. Identification of a novel CpG DNA class and motif that optimally stimulate B cell and plasmacytoid dendritic cell functions. J. Leukocyte Biol. 73, 781-792.

Matsuoka, N., Nishikawa, M., Mohri, K., Rattanakiat, S., Takakura, Y., 2010. Structural and immunostimulatory properties of Y-shaped DNA consisting of phosphodiester and phosphorothioate oligodeoxynucleotides. J. Control. Release. 148, 311-316.

Matzinger, P., 1994. Tolerance, danger, and the extended family. Annu. Rev. Immunol. 12, 991-1045.

Mohri, K., Nishikawa, M., Takahashi, N., Shiomi, T., Matsuoka, N., Ogawa, K., Endo, 
M., Hidaka, K., Sugiyama, H., Takahashi, Y., Takakura, Y., 2012a. Design and development of nanosized DNA assemblies in polypod-like structures as efficient vehicles for immunostimulatory $\mathrm{CpG}$ motifs to immune cells. ACS Nano 6, 5931-5940.

Mohri, K., Takahashi, N., Nishikawa, M., Kusuki, E., Shiomi, T., Takahashi, Y., Takakura, Y., 2012b. Increased immunostimulatory activity of polypod-like structured DNA by ligation of the terminal loop structures. J. Control. Release. 163, 285-292.

Monteith, D.K., Horner, M.J., Gillett, N.A., Butler, M., Geary, R., Burckin, T., Ushiro-Watanabe, T., Levin, A.A., 1999. Evaluation of the renal effects of an antisense phosphorothioate oligodeoxynucleotide in monkeys. Toxicol Pathol. 27, 307-317.

Nayak, S., Lyon, L.A., 2005. Soft nanotechnology with soft nanoparticles. Angew. Chem. Int. Ed. Engl. 44, 7686-7708.

Nishikawa, M., Matono, M., Rattanakiat, S., Matsuoka, N., Takakura, Y., 2008. Enhanced immunostimulatory activity of oligodeoxynucleotides by Y-shape formation. Immunology 124, 247-255.

Nishikawa, M., Mizuno, Y., Mohri, K., Matsuoka, N., Rattanakiat, S., Takahashi, Y., Funabashi, H., Luo, D., Takakura, Y., 2011. Biodegradable CpG DNA hydrogels for sustained delivery of doxorubicin and immunostimulatory signals in tumor-bearing mice. Biomaterials 32, 488-494.

Nishikawa, M., Rattanakiat, S., Takakura, Y., 2010. DNA-based nano-sized systems for pharmaceutical and biomedical applications. Adv. Drug Deliv. Rev. 62, 626-632.

Ozinsky, A., Underhill, D.M., Fontenot, J.D., Hajjar, A.M., Smith, K.D., Wilson, C.B., Schroeder, L., Aderem, A., 2000. The repertoire for pattern recognition of pathogens by the innate immune system is defined by cooperation between toll-like receptors. Proc. Natl. Acad. Sci. U.S.A. 97, 13766-13771.

Poeck, H., Besch, R., Maihoefer, C., Renn, M., Tormo, D., Morskaya, S.S., Kirschnek, S., Gaffal, E., Landsberg, J., Hellmuth, J., Schmidt, A., Anz, D., Bscheider, M., Schwerd, T., Berking, C., Bourquin, C., Kalinke, U., Kremmer, E., Kato, H., Akira, S., Meyers, R., Häcker, G., Neuenhahn, M., Busch, D., Ruland, J., Rothenfusser, S., Prinz, M., Hornung, V., Endres, S., Tüting, T., Hartmann, G., 2008. 5'-Triphosphate-siRNA: turning gene silencing and Rig-I activation against melanoma. Nat. Med. 14, 1256-1263.

Poeck, H., Wagner, M., Battiany, J., Rothenfusser, S., Wellisch, D., Hornung, V., Jahrsdorfer, B., Giese, T., Endres, S., Hartmann, G., 2004. Plasmacytoid dendritic 
cells, antigen, and CpG-C license human B cells for plasma cell differentiation and immunoglobulin production in the absence of T-cell help. Blood 103, 3058-3064.

Rakoff-Nahoum, S., Paglino, J., Eslami-Varzaneh, F., Edberg, S., Medzhitov, R., 2004. Recognition of commensal microflora by Toll-like receptors is required for intestinal homeostasis. Cell 118, 229-241.

Rankin, R., Pontarollo, R., Ioannou, X., Krieg, A.M., Hecker, R., Babiuk, L.A., van Drunen Little-van den Hurk, S., 2001. CpG motif identification for veterinary and laboratory species demonstrates that sequence recognition is highly conserved. Antisense Nucleic Acid Drug Dev. 11, 333-340.

Rattanakiat, S., Nishikawa, M., Funabashi, H., Luo, D., Takakura, Y., 2009. The assembly of a short linear natural cytosine-phosphate-guanine DNA into dendritic structures and its effect on immunostimulatory activity. Biomaterials 30, 5701-5706.

Roh, Y.H., Lee, J.B., Kiatwuthinon, P., Hartman, M.R., Cha, J.J., Um, S.H., Muller, D.A., Luo, D., 2011a. DNAsomes: Multifunctional DNA-based nanocarriers. Small 7, 74-78.

Roh, Y.H., Ruiz, R.C., Peng, S., Lee, J.B., Luo, D., 2011b. Engineering DNA-based functional materials. Chem. Soc. Rev. 40, 5730-5744.

Rothemund, P.W., 2006. Folding DNA to create nanoscale shapes and patterns. Nature 440, 297-302.

Sands, H., Gorey-Feret, L.J., Cocuzza, A.J., Hobbs, F.W., Chidester, D., Trainor, G.L., 1994. Biodistribution and metabolism of internally 3H-labeled oligonucleotides. I. Comparison of a phosphodiester and a phosphorothioate. Mol. Pharmacol. 45, 932-943.

Schlee, M., Roth, A., Hornung, V., Hagmann, C.A., Wimmenauer, V., Barchet, W., Coch, C., Janke, M., Mihailovic, A., Wardle, G., Juranek, S., Kato, H., Kawai, T., Poeck, H., Fitzgerald, K.A., Takeuchi, O., Akira, S., Tuschl, T., Latz, E., Ludwig, J., Hartmann, G., 2009. Recognition of 5' triphosphate by RIG-I helicase requires short blunt double-stranded RNA as contained in panhandle of negative-strand virus. Immunity 31, 25-34.

Schmidt, M., Anton, K., Nordhaus, C., Junghans, C., Wittig, B., Worm, M., 2006. Cytokine and Ig-production by CG-containing sequences with phosphorodiester backbone and dumbbell-shape. Allergy 61, 56-63.

Schüller, V.J., Heidegger, S., Sandholzer, N., Nickels, P.C., Suhartha, N.A., Endres, S., Bourquin, C., Liedl, T., 2011. Cellular immunostimulation by $\mathrm{CpG}$-sequence-coated DNA origami structures. ACS Nano 5, 9696-9702.

Seeman, N.C. 1982. Nucleic acid junctions and lattices. J. Theor. Biol. 99, 237-247. 
Seeman, N.C., 2010. Nanomaterials based on DNA. Annu. Rev. Biochem. 79, 65-87.

Shinagawa, H., Iwasaki, H., 1995. Molecular mechanisms of Holliday junction processing in Escherichia coli. Adv. Biophys. 31, 49-65.

Simmel, F.C., 2012. DNA-based assembly lines and nanofactories. Curr. Opin. Biotechnol. 23, 516-521.

Smolarczyk, R., Cichoń, T., Sochanik, A., Szala, S., 2005. Negligible induction of IFN-gamma, IL-12 and TNF-alpha by DNA-PEI $750 \mathrm{kDa} /$ albumin complexes. Cytokine 29, 283-287.

Smyth, M.J., Taniguchi, M., Street, S.E., 2000. The anti-tumor activity of IL-12: mechanisms of innate immunity that are model and dose dependent. J. Immunol. $165,2665-2670$.

Stein, C.A., Subasinghe, C., Shinozuka, K., Cohen, J.S., 1988. Physicochemical properties of phosphorothioate oligodeoxynucleotides. Nucleic Acids Res. 16, 3209-3221.

Swiecki, M., McCartney, S.A., Wang, Y., Colonna, M., 2011. TLR7/9 versus TLR3/MDA5 signaling during virus infections and diabetes. J. Leukoc. Biol. 90, 691-701.

Takakura, Y., Nishikawa, M., Yamashita, F., Hashida, M., 2001. Development of gene drug delivery systems based on pharmacokinetic studies. Eur. J. Pharm. Sci. 13, 71-76.

Takaoka, A., Wang, Z., Choi, M.K., Yanai, H., Negishi, H., Ban, T., Lu, Y., Miyagishi, M., Kodama, T., Honda, K., Ohba, Y., Taniguchi, T., 2007. DAI (DLM-1/ZBP1) is a cytosolic DNA sensor and an activator of innate immune response. Nature 448, 501-505.

Tokunaga, T., Yamamoto, S., Namba, K., 1988. A synthetic single-stranded DNA, poly $(\mathrm{dG}, \mathrm{dC})$, induces interferon-alpha/beta and -gamma, augments natural killer activity, and suppresses tumor growth. Jpn J. Cancer. Res. 79, 682-686.

Tomita, N., Ogihara, T., Morishita, R., 2003. Transcription factors as molecular targets: molecular mechanisms of decoy ODN and their design. Curr. Drug Targets 4, 603-608.

Tsai, C.Y., Lu, S.L., Hu, C.W., Yeh, C.S., Lee, G.B., Lei, H.Y., 2012. Size-dependent attenuation of TLR9 signaling by gold nanoparticles in macrophages. J. Immunol. $188,68-76$.

Uematsu, S., Akira, S., 2007. Toll-like receptors and Type I interferons. J. Biol. Chem. 282, 15319-15323.

Um, S.H., Lee, J.B., Park, N., Kwon, S.Y., Umbach, C.C., Luo, D., 2006. 
Enzyme-catalysed assembly of DNA hydrogel. Nat. Mater. 5, 797-801.

Uno, S., Nishikawa, M., Mohri, K., Umeki, Y., Matsuzaki, N., Takahashi, Y., Fujita, H., Kadowaki, N., Takakura, Y., Efficient delivery of immunostimulatory DNA to mouse and human immune cells through the construction of polypod-like structured DNA. Nanomedicine, in press.

Vollmer, J., Weeratna, R., Payette, P., Jurk, M., Schetter, C., Laucht, M., Wader, T., Tluk, S., Liu, M., Davis, H. L., Krieg, A. M., 2004. Characterization of three CpG oligodeoxynucleotide classes with distinct immunostimulatory activities. Eur. J. Immunol. 34, 251-262.

Wagner, R.W., 1994. Gene inhibition using antisense oligodeoxynucleotides. Nature 372, 333-335.

Wang, Z., Choi, M.K., Ban, T., Yanai, H., Negishi, H., Lu, Y., Tamura, T., Takaoka, A., Nishikura, K., Taniguchi, T., 2008. Regulation of innate immune responses by DAI (DLM-1/ZBP1) and other DNA-sensing molecules. Proc. Natl. Acad. Sci. U.S.A. $105,5477-5482$.

Watson, J.D., Crick, F.H., 1974. Molecular structure of nucleic acids: a structure for deoxyribose nucleic acid. Nature 248, 765.

Wu, D.Y., Wallace, R.B., 1989. Specificity of the nick-closing activity of bacteriophage T4 DNA ligase. Gene. 76, 245-254.

Yang, L., Wu, X., Wan, M., Yu, Y., Yu, Y., Wang, L., 2013. CpG oligodeoxynucleotides with double stem-loops show strong immunostimulatory activity. Int. Immunopharmacol. 15, 89-96.

Yi, A.K., Chang, M., Peckham, D.W., Krieg, A.M., Ashman, R.F., 1998. CpG oligodeoxyribonucleotides rescue mature spleen B cells from spontaneous apoptosis and promote cell cycle entry. J. Immunol. 160, 5898-5906.

Yi, A.K., Klinman, D.M., Martin, T.L., Matson, S., Krieg, A.M., 1996. Rapid immune activation by $\mathrm{CpG}$ motifs in bacterial DNA. Systemic induction of IL-6 transcription through anantioxidant-sensitive pathway. J. Immunol. 157, 5394-5402.

Zhang, C., Ko, S.H., Su, M., Leng, Y., Ribbe, A.E., Jiang, W., Mao, C., 2009. Symmetry controls the face geometry of DNA polyhedra. J. Am. Chem. Soc. 131, 1413-1415.

Zhang, C., Su, M., He, Y., Leng, Y., Ribbe, A.E., Wang, G., Jiang, W., Mao, C., 2010. Exterior modification of a DNA tetrahedron. Chem. Commun. 46, 6792-6794.

Zhang, C., Su, M., He, Y., Zhao, X., Fang, P.A., Ribbe, A.E., Jiang, W., Mao, C., 2008. Conformational flexibility facilitates self-assembly of complex DNA nanostructures. Proc Natl Acad Sci U.S.A. 105, 10665-10669.

Zhao, Y.X., Shaw, A., Zeng, X., Benson, E., Nyström, A.M., Högberg, B., 2012. DNA 
origami delivery system for cancer therapy with tunable release properties. ACS Nano 6, 8684-8691. 


\section{Figure legends}

Figure 1. DNA ligase-catalyzed reaction and schematic representations of DNA assemblies. In most cases, double-strand formation between two DNA molecules acts as the driving force for the formation of DNA assemblies. (A) Two double-stranded DNA molecules can be connected by hybridization through the sticky ends (5'-GTCA-3' and 5'-TGAC-3' in this case). The nick between the two double-stranded DNA molecules can be enzymatically ligated, to produce one double-stranded DNA. (B) The sequence and planar presentation of Y-DNA and X-DNA. (C) Schematic representations of a variety of DNA assemblies. Tetrahedral DNA (left) (He et al., 2008), hexahedral DNA (middle) (Chen and Seeman, 1991), and icosahedral DNA (right) (He et al., 2010).

Figure 2. DNA- or RNA-mediated stimulation of innate immunity. DNA or RNA is taken up by immune cells via endocytosis. In endosomes, TLR3, TLR7/8, or TLR9 recognizes double-stranded RNA, single-stranded RNA, or CpG DNA, respectively. RIG-I or DAI recognizes single-stranded triphosphate RNA or double-stranded DNA, respectively, in the cytoplasm. These interactions activate the NF-kB or IRFs, resulting in the production of proinflammatory cytokines and IFNs.

Figure 3. Schematic illustration of DNA assemblies for the delivery of CpG DNA. (A) Polypod-like DNA (polypodna) with three (tripodna) to twelve (dodecapodna) pods. (B) First to third generations (G1 to G3) of dendrimer-like DNA (DL-DNA). (C) DNA hydrogel and its scanning electron microscope (SEM) image. 
A
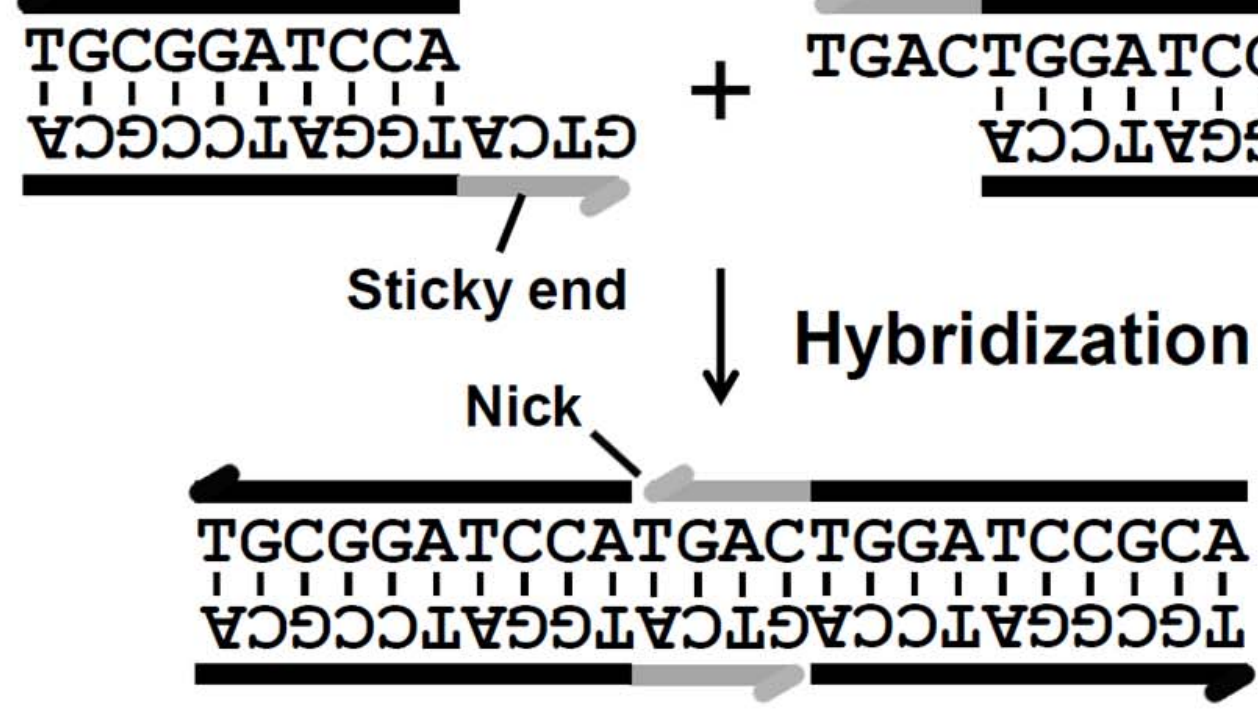

$\downarrow$ Enzymatic ligation

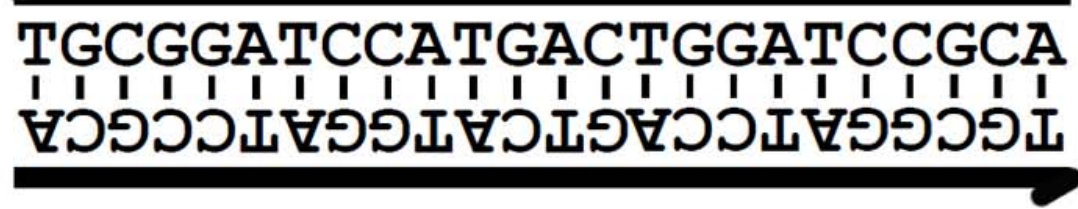

C

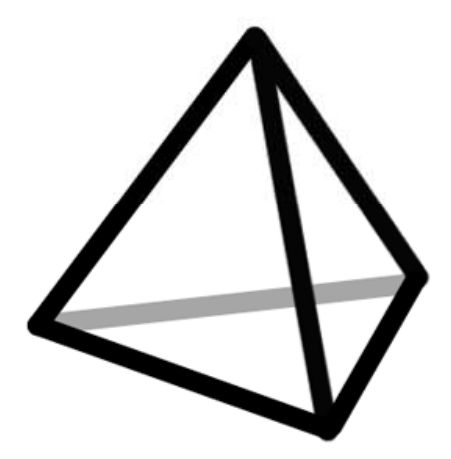

+ TGACTGGATCCGCA

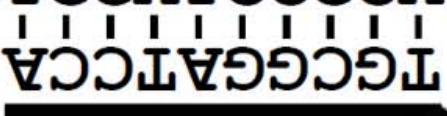

$\downarrow$ Hybridization

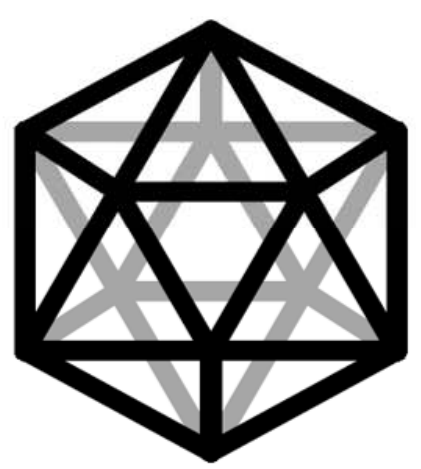

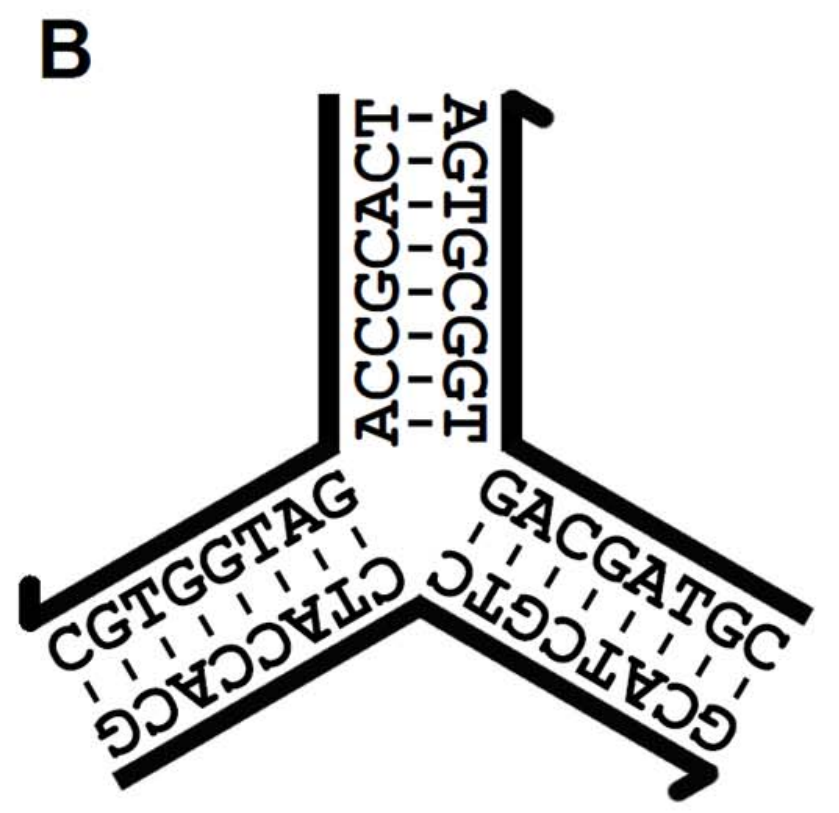

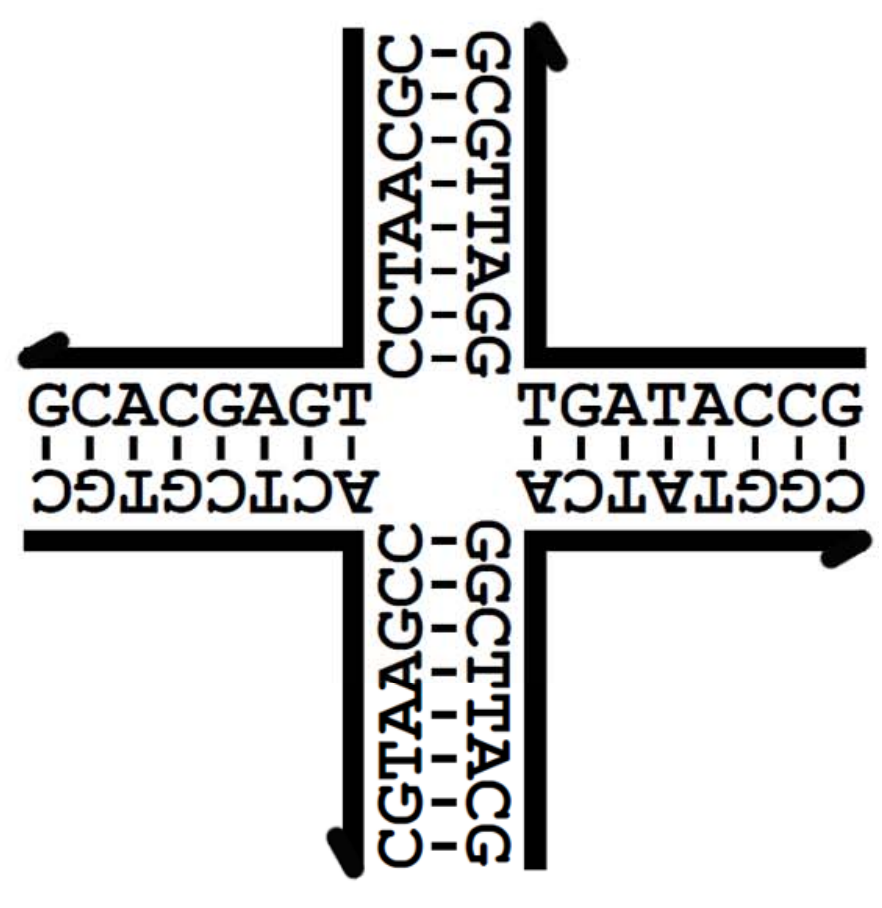

Figure 1

TGATACCG

I II I

U-a

ป-

-1-

4-1

政

U-口 


\section{DNA or RNA}

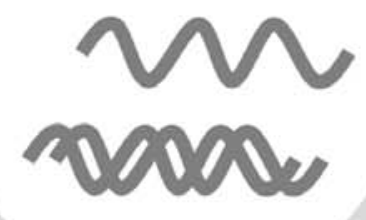

\section{Cytoplasm}

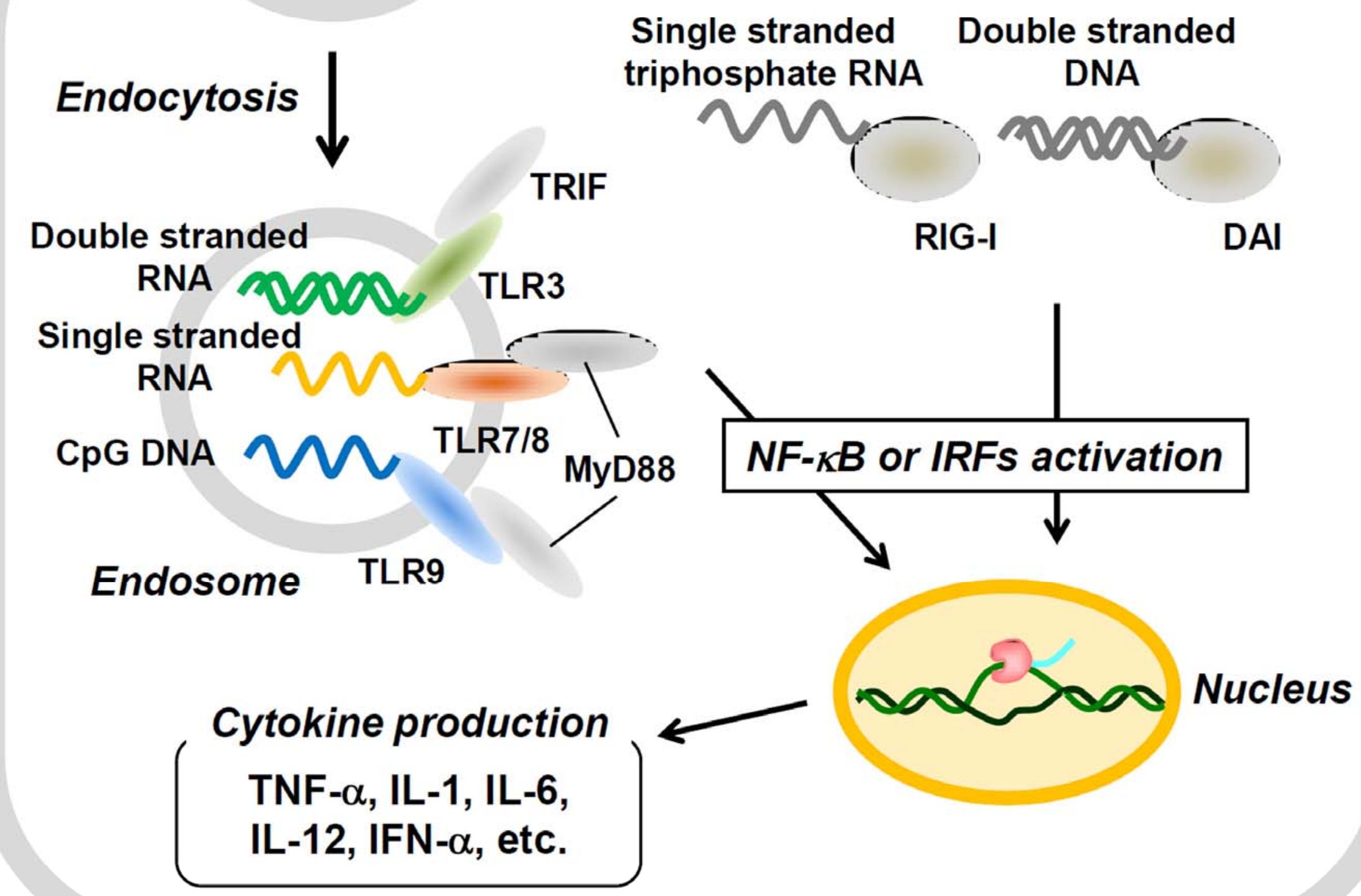

Figure 2 
A

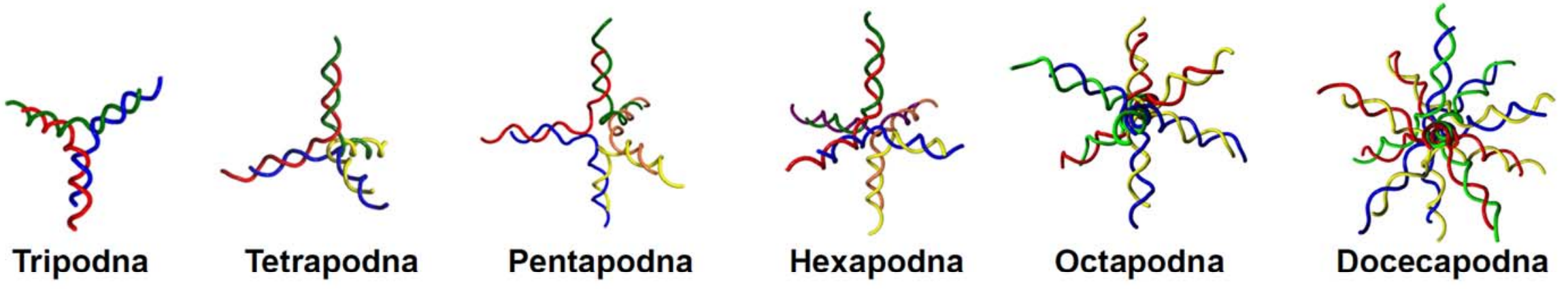

B

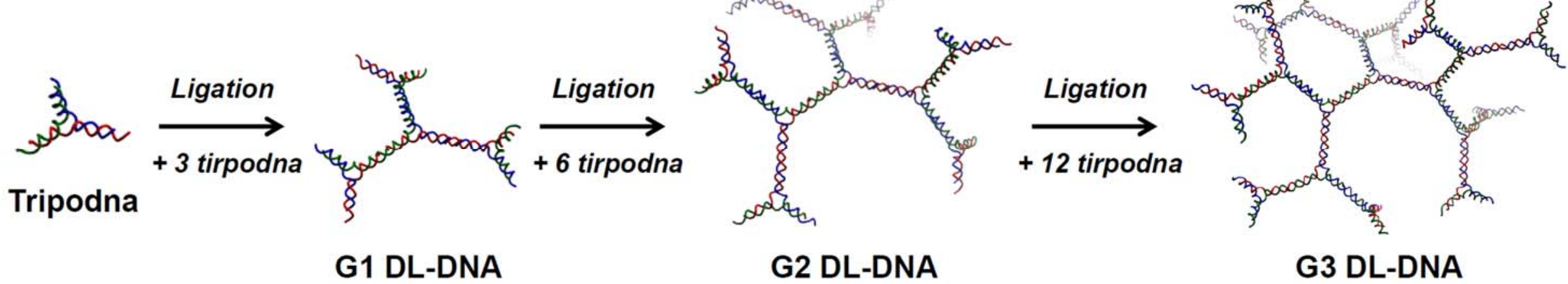

C

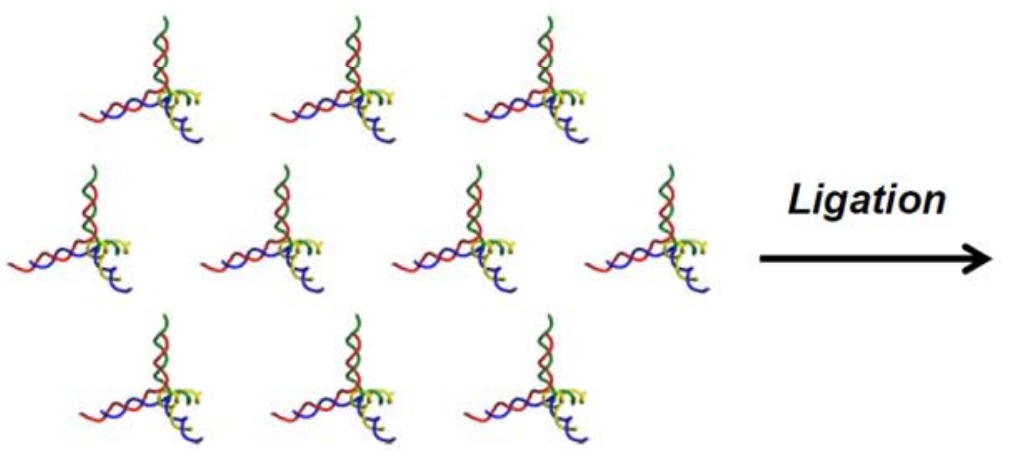

Tetrapodna

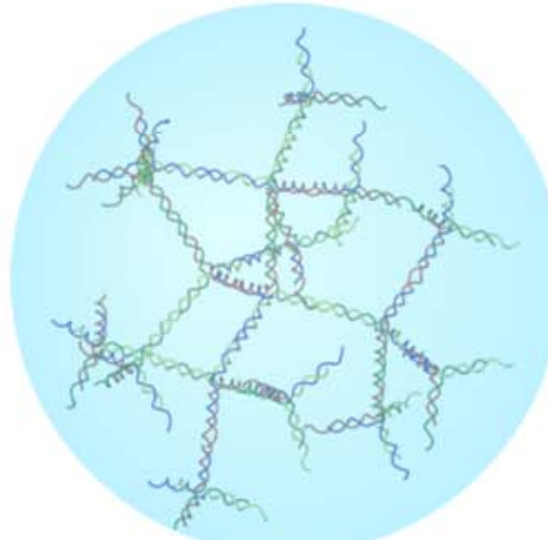

DNA hydrogel

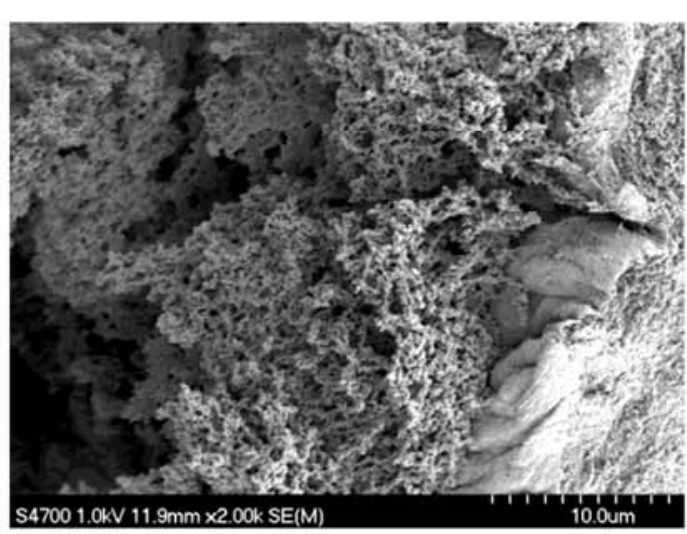

SEM image of DNA hydrogel

Figure 3 
Table 1. DNA nanostructures used for drug delivery

\begin{tabular}{|c|c|c|c|c|}
\hline $\begin{array}{l}\text { DNA } \\
\text { nanostructure }\end{array}$ & Cargo & Size & Advantage & Reference \\
\hline Tetrahedral DNA & Antisense DNA & $\sim 7 \mathrm{~nm}$ & High cellular uptake & $\begin{array}{l}\text { Keum et al. } \\
\text { (2011) }\end{array}$ \\
\hline Tetrahedral DNA & siRNA & $\sim 29 \mathrm{~nm}$ & $\begin{array}{l}\text { Long blood } \\
\text { circulation, tumor } \\
\text { targeting }\end{array}$ & $\begin{array}{l}\text { Lee et al. } \\
(2012)\end{array}$ \\
\hline DNAsome & siRNA, Doxorubicin & $110-1,100 \mathrm{~nm}$ & $\begin{array}{l}\text { High loading } \\
\text { capacity and } \\
\text { efficiency }\end{array}$ & $\begin{array}{l}\text { Roh et al. } \\
\text { (2011a) }\end{array}$ \\
\hline DNA hydrogel & Insulin & - & Sustained release & $\begin{array}{l}\text { Um et al. } \\
\text { (2006) }\end{array}$ \\
\hline DNA triangle & Doxorubicin & - & $\begin{array}{l}\text { High loading } \\
\text { efficiency }\end{array}$ & $\begin{array}{l}\text { Jiang et al. } \\
(2012)\end{array}$ \\
\hline $\begin{array}{l}\text { DNA origami } \\
\text { tube }\end{array}$ & Doxorubicin & $380 \mathrm{~nm}$ & $\begin{array}{l}\text { High loading } \\
\text { efficiency }\end{array}$ & $\begin{array}{l}\text { Jiang et al. } \\
(2012)\end{array}$ \\
\hline $\begin{array}{l}\text { DNA origami } \\
\text { tube }\end{array}$ & Doxorubicin & $138 \mathrm{~nm} \times 13 \mathrm{~nm}$ & $\begin{array}{l}\text { High loading } \\
\text { efficiency }\end{array}$ & $\begin{array}{l}\text { Zhao et al. } \\
\text { (2012) }\end{array}$ \\
\hline $\begin{array}{l}\text { Hexagonal DNA } \\
\text { barrel }\end{array}$ & $\begin{array}{l}\text { Gold nanoparticle, } \\
\text { antibody }\end{array}$ & $\begin{array}{l}35 \mathrm{~nm} \times 35 \mathrm{~nm} \\
\times 45 \mathrm{~nm}\end{array}$ & Sensing cell surface & $\begin{array}{l}\text { Douglas et al. } \\
\text { (2012) }\end{array}$ \\
\hline
\end{tabular}

